\section{Naturally Occurring Anti-TB Agents: Isolation, Chemical Transformations and In Vitro Antitubercular Activities of Secondary Metabolites of Rhizomes of Alpinia galanga}

\author{
Tushar R. Valkute ${ }^{1}$, Manisha Arkile ${ }^{2}$, Dhiman Sarkar ${ }^{2}$, Asish K. \\ Bhattacharya ${ }^{1}$ \\ ${ }^{1}$ Division of Organic Chemistry, CSIR-National Chemical Laboratory \\ (CSIR-NCL), Pune, India \\ ${ }^{2}$ Combi-Chem Bioresource Centre, CSIR-National Chemical Labora- \\ tory (CSIR-NCL), Pune, India
}

\section{Abstract \\ $\nabla$}

A bioactivity-guided chemical examination of the acetone extract of the rhizomes of Alpinia galanga led to the isolation of six secondary metabolites, eucalyptol derivative (1) and phenylpropanoids (2-6). The structures of all of the isolated compounds (16) were elucidated on the basis of their spectral data. The isolated compounds (1-6) were in vitro assayed against active and dormant phenotypes of Mycobacterium tuberculosis H37Ra, respectively. Interestingly, 1'S-1'-acetoxychavicol acetate (2) showed good antitubercular activities against both active and dormant phenotypes of $M$. tuberculosis with $\mathrm{IC}_{50}$ values of $1.04 \mu \mathrm{M}$ and $2.69 \mu \mathrm{M}$, respectively. Tsuji-Trost and homodimerization reactions of the active compound ( 2 ) respectively resulted in the formation of two analogues, $\mathbf{7}$ and $\mathbf{8}$. Both of these synthesized analogues were also found to be active in vitro against active $\left[\mathrm{IC}_{50} \mathrm{~S}\right.$ of 3.24 and $3.87 \mu \mathrm{M}$, respectively, for compounds 7 and 8 ] and dormant [ $\mathrm{IC}_{50} \mathrm{~s}$ of 8.33 and $2.41 \mu \mathrm{M}$, respectively, for compounds 7 and 8] phenotypes of $M$. tuberculosis H37Ra, respectively.

Key words

Alpinia galanga $\cdot$ Zingiberaceae $\cdot$ phenyl propanoids $\cdot$ natural products $\cdot$ antitubercular activity

Supporting information available online at http://www.thieme-connect.de/products

Tuberculosis (TB), an infectious disease caused by Mycobacterium tuberculosis (MTB), is a leading cause of death worldwide. The World Health Organization (WHO) reported [1] that approximately 9 million people were infected with TB globally in the year 2013 alone, which resulted in 1.5 million deaths, out of which an estimated 360000 were infected with both human immunodeficiency virus (HIV) as well as tuberculosis. It is estimated that more than half of the TB-infected population is from Southeast Asia and Western Pacific Regions with China and India alone accounting for $11 \%$ and $24 \%$ of total cases, respectively. The treatment requires long spells due to which several patients discontinue the treatment in between, which results in the development of multidrug resistance (MDR) and extensively drug-resistant (XDR) TB. Both of these forms of TB are highly fatal, and the treatment is both expensive and complicated, thereby further complicating the prevention, control, and treatment of TB [2-4]. Although, at present, isoniazid, ethambutol, pyrazinamide, and rifampicin are available as effective anti-TB drugs, the threat posed by the development of multidrug resistance tuberculosis (MDR-TB) against the first-line as well as the second-line drugs is a serious issue $[5,6]$. Hence, the need for the development of new naturally occurring molecules to effectively treat TB and also address MDR and XDR assumes significance.

The Zingiberaceae plant, Alpinia galanga (L.) Willd., is commonly known as galangal and is widely cultivated in China, India, and Southeast Asian countries such as Thailand, Indonesia, and the Philippines $[7,8]$. The rhizomes of this plant are extensively used as a spice or ginger substitute for flavoring foods. The rhizome has found several uses in the traditional system of medicine such as stomachic in China, or for carminative, antiflatulent, antifungal, and anti-itching in Thailand. In India, it has been traditionally used as a nervine tonic and for a stimulant effect [9]. Also, the use of the extract of the rhizome as an aphrodisiac, anti-inflammatory, revulsive, antiproliferative activity, antioxidant, anticholinergic, immunostimulating activity, hypoglycemic, and antimicrobial has been reported [8-17]. The chemical examination of A. galanga has resulted in the isolation of several bioactive molecules [18-35]. The pungent principal compound 1'S-1'-acetoxychavicol acetate (2) of $A$. galanga has been reported to possess various biological activities, such as antioxidative [36], antitumor [37-41], anti-inflammatory [42], xanthine oxidase inhibitory activity [43], and antifungal [44].

In continuation of our work on naturally occurring bioactive secondary metabolites [45-49], we initiated a systematic chemical examination of $A$. galanga for its antitubercular secondary metabolites. The dried rhizomes of $A$. galanga were successively extracted with acetone and $\mathrm{MeOH}$ to furnish acetone and $\mathrm{MeOH}$ extracts, respectively, which were assayed against both active and dormant phenotypes of $M$. tuberculosis. The acetone extract showed antitubercular activity ( $\odot$ Table 1 ) against both the active and dormant phenotypes of $M$. tuberculosis with $\mathrm{MIC}_{90}\left(\mathrm{IC}_{50}\right)$ values of 17.80 (10.44) and 18.27 (10.87) $\mu \mathrm{M}$, respectively, however, the $\mathrm{MeOH}$ extract was found to be totally inactive. Bioactive crude acetone was taken up for the isolation of the bioactive secondary metabolites and was fractionated over $\mathrm{SiO}_{2}$ column (100200 mesh) into nine fractions (A-I). Fraction B was flash chromatographed using a RediSep ${ }^{\circledR}$ column $\left(\mathrm{SiO}_{2}, 12 \mathrm{~g}\right)$ to furnish a pale yellow viscous oil that was identified as 2 -acetoxy-1,8-cineole (1) by comparison with its reported spectral data [20,22]. Silica gel column chromatography of fraction $C$ resulted in 12 subfractions (C1 to C12). These subfractions were further flash chromatographed and resulted in the isolation of four compounds that were identified on the basis of their spectral data as 1 'S-1'-acetoxychavicol acetate (2) [24-25,29,34], trans-p-coumaryl diacetate (3) [24,29], 1'S-1'-acetoxyeugenol acetate (4) [24, 29, 34,43], and trans-coniferyl diacetate (5) [43]. Further, fraction D on flash chromatography furnished a viscous liquid that was identified as 1 'S-1'-hydroxychavicol acetate (6) by comparison with its reported spectral data $[24,29]$.

The isolated compounds 1-6 ( $\bullet$ Fig. 1) were assayed in vitro against active and dormant phenotypes of $M$. tuberculosis H37Ra, respectively, using an established XTT reduction menadione assay (XRMA) antitubercular screening protocol [50-52]. The first-line antitubercular drug rifampicin (Sigma) was used as a reference standard and data obtained are presented in $\odot$ Table 1. Interestingly, 1'S-1'-acetoxychavicol acetate (2) was found to be the most active amongst all of the isolated metabolites against both active and dormant phenotypes of $M$. tuberculosis, having IC $_{50}$ values of $1.04 \mu \mathrm{M}$ and $2.69 \mu \mathrm{M}$, respectively. However, out of 
Table 1 In vitro antitubercular activity of pure isolated compounds (1-6) and their synthetic analogues (7 and 8).

\begin{tabular}{|c|c|c|c|c|}
\hline \multirow[t]{3}{*}{ Extract/Compound } & \multicolumn{4}{|c|}{ Antitubercular activity against $M$. tuberculosis $\mathrm{H} 37 \mathrm{Ra}$ in $\mu \mathrm{M}$ with SD values } \\
\hline & \multicolumn{2}{|l|}{ Active state } & \multicolumn{2}{|c|}{ Dormant state } \\
\hline & $\mathrm{MIC}_{90}$ & $\mathrm{IC}_{50}(\mu \mathrm{M})$ & $\mathrm{MIC}_{90}$ & $\mathrm{IC}_{50}(\mu \mathrm{M})$ \\
\hline Acetone ext. & $17.80 \pm 0.17$ & $10.44 \pm 0.37$ & $18.27 \pm 1.02$ & $10.87 \pm 0.57$ \\
\hline MeOH ext. & NA & - & NA & - \\
\hline 1 & NA & - & NA & - \\
\hline 2 & $3.27 \pm 0.08$ & $1.04 \pm 0.04$ & $4.73 \pm 0.58$ & $2.69 \pm 0.14$ \\
\hline 3 & $40.95 \pm 1.05$ & $25.04 \pm 1.36$ & $60.11 \pm 1.20$ & $27.12 \pm 1.10$ \\
\hline 4 & $9.18 \pm 1.29$ & $5.04 \pm 0.23$ & $8.53 \pm 0.20$ & $5.40 \pm 0.40$ \\
\hline 5 & $23.16 \pm 1.19$ & $17.38 \pm 0.65$ & $15.07 \pm 0.78$ & $7.80 \pm 1.44$ \\
\hline 6 & $21.98 \pm 0.09$ & $7.98 \pm 1.13$ & $21.03 \pm 0.20$ & $9.33 \pm 0.20$ \\
\hline 7 & $14.53 \pm 1.88$ & $3.24 \pm 0.71$ & $11.98 \pm 1.10$ & $8.33 \pm 0.20$ \\
\hline 8 & $5.01 \pm 0.41$ & $3.87 \pm 0.61$ & $4.04 \pm 0.30$ & $2.41 \pm 0.30$ \\
\hline Rifampicin & 0.048 & 0.0018 & 0.043 & 0.0014 \\
\hline
\end{tabular}

NA: not active; both $\mathrm{IC}_{50}$ and $\mathrm{MIC}_{90}$ are $>100 \mu \mathrm{g} / \mathrm{mL}$; SD $( \pm)$ : standard deviation<smiles>CC(=O)O[C@H]1C2CC3(C)OC1(C)C3(C)C2</smiles>

1<smiles>C=CC(OC(C)=O)c1ccc(OC(C)=O)c(OC)c1</smiles>

4

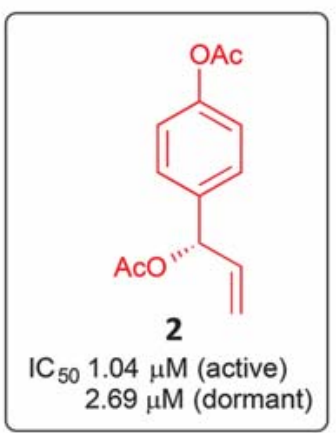<smiles>COc1ccc(/C=C/COC(C)=O)cc1OC</smiles>

5<smiles>CC(=O)OC/C=C/c1ccc(OC(C)=O)cc1</smiles>

Fig. 1 Isolated compounds (1-6) from the acetone extract of the rhizomes of $A$. galanga. all of the isolated secondary metabolites viz. trans-p-coumaryl diacetate (3), 1'S-1'-acetoxyeugenol acetate (4), trans-coniferyl diacetate (5), and 1 'S-1'-hydroxychavicol acetate (6), only compound 4 showed moderate activities with $\mathrm{IC}_{50}$ values of $5.04 \mu \mathrm{M}$ and $5.40 \mu \mathrm{M}$ against active and dormant phenotypes of M. tuberculosis, respectively.

Since compound 2, 1'S-1'-acetoxychavicol acetate (yield $562 \mathrm{mg}$ ), showed antitubercular activities compared to other isolated secondary metabolites against both active and dormant phenotypes of $M$. tuberculosis, we thought of carrying out synthesis of the analogues of 1 'S-1'-acetoxychavicol acetate (2) and evaluate their in vitro antitubercular activities in order to further improve activities. The presence of allylic acetate's functionality in compound $\mathbf{2}$ prompted us to attempt a palladium-catalyzed TsujiTrost reaction [53] to synthesize its analogue (7) via a $\mathrm{C}-\mathrm{C}$ bondforming reaction ( Fig.2). Reaction of 1 'S-1'-acetoxychavicol acetate ( 2 ) with cyclohexanone in DMSO catalyzed by $\mathrm{Pd}(\mathrm{OAc})_{2}$ at room temperature furnished a reaction mixture that was flash chromatographed using RediSep ${ }^{\circledR}$ column $\left(\mathrm{SiO}_{2}, 12 \mathrm{~g}\right)$ and eluted with petroleum ether: ethyl acetate $(0 \rightarrow 10 \%)$ to furnish compound 7 as a viscous liquid (37\%). Homodimerization [54] of compound 2 was carried out using Grubb's Ist generation catalyst to furnish homodimer $8(91 \%)$ as a colorless solid [m.p. $83-85^{\circ} \mathrm{C}$; $\left.[\alpha]_{\mathrm{D}}^{25}-36.6\left(c 1, \mathrm{CHCl}_{3}\right)\right]$.

The synthesized analogues $\mathbf{7}$ and $\mathbf{8}$ were assayed in vitro against both active and dormant phenotypes of $M$. tuberculosis for their antitubercular activities ( $\bigcirc$ Table 1 ). Both compounds showed in vitro antitubercular activities. Compound 7 was found to possess IC $_{50}$ values of $3.24 \mu \mathrm{M}$ and $8.33 \mu \mathrm{M}$, whereas compound 8 had $\mathrm{IC}_{50}$ values of $3.87 \mu \mathrm{M}$ and $2.41 \mu \mathrm{M}$ against active and dormant phenotypes of $M$. tuberculosis, respectively. 


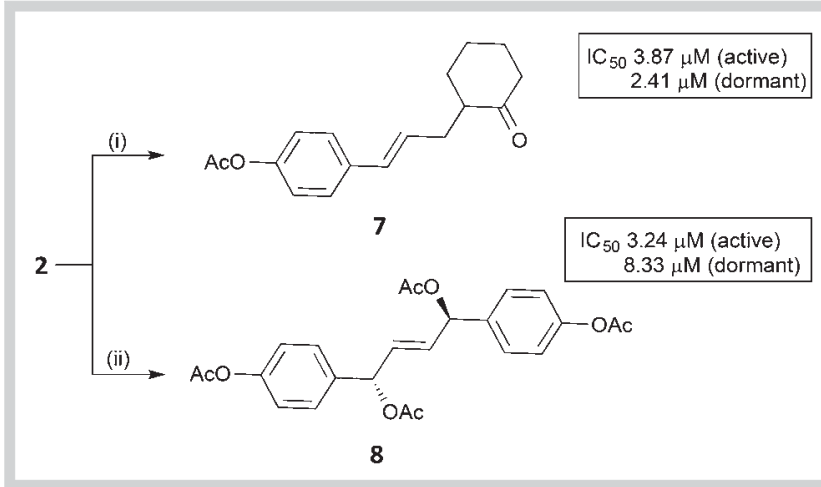

Fig. 2 Scheme of the preparation of derivatives of $\mathbf{2}$. Reagents and conditions: (i) $\mathrm{Pd}(\mathrm{OAc})_{2}, \mathrm{PPh}_{3}$, DMSO, cyclohexanone, pyrrolidine, rt, $3 \mathrm{~h}, 37 \%$; (ii) Grubb's lst generation catalyst, $\mathrm{CH}_{2} \mathrm{Cl}_{2}$, rt, 16 h, $91 \%$.

\section{Materials and Methods}

$\nabla$

Plant material

The rhizomes of A. galanga were collected and identified by Prof. Kornkanok Ingkainan, Department of Pharmaceutical Chemistry and Pharmacognosy, Faculty of Pharmaceutical Sciences, Naresuan University, Thailand from Phitsanulok, Thailand in May 2008. A herbarium specimen (003566) is being maintained at the Department of Biology, Faculty of Pharmaceutical Sciences, Naresuan University, Thailand.

\section{Synthesis of compound 7}

A mixture of 1'S-1'-acetoxychavicol acetate (2; $40 \mathrm{mg}, 0.5 \mathrm{mmol})$, $\mathrm{Pd}(\mathrm{OAc})_{2}(10 \mathrm{~mol} \%)$, and ligand $\mathrm{PPh}_{3}(25 \mathrm{mg})$ in DMSO $(2 \mathrm{~mL})$ was stirred at room temperature for $5 \mathrm{~min}$. Next, cyclohexanone (1.5 mmol, 3 equiv.) and pyrrolidine (30 mol\%) were added and the reaction mixture was further stirred at room temperature for $3 \mathrm{~h}$. After completion of the reaction (TLC), the reaction mixture was quenched with $\mathrm{H}_{2} \mathrm{O}(5 \mathrm{~mL})$ and was extracted with EtOAc $(3 \times 25 \mathrm{~mL})$. The organic layers were pooled together and washed with brine solution $(1 \times 25 \mathrm{~mL})$. The organic layer was dried over anhydrous $\mathrm{Na}_{2} \mathrm{SO}_{4}$, filtered, and concentrated under reduced pressure. The crude reaction mixture was flash chromatographed using a RediSep ${ }^{\circledR}$ column $\left(\mathrm{SiO}_{2}, 12 \mathrm{~g}\right)$ and eluted with petroleum ether: ethyl acetate $(0 \rightarrow 10 \%)$ to furnish pure compound 7 as a viscous liquid $(17 \mathrm{mg}, 37 \%) ; R_{\mathrm{f}} 0.30$ (EtOAc-petroleum ether, $1: 4) ;[\alpha]_{\mathrm{D}}^{25}+0.23\left(c 1, \mathrm{CHCl}_{3}\right) ;{ }^{1} \mathrm{H}$ NMR $(200 \mathrm{MHz}$, $\left.\mathrm{CDCl}_{3}\right) \delta_{\mathrm{H}}: 7.33(\mathrm{~d}, J=8.6 \mathrm{~Hz}, 2 \mathrm{H}), 7.00(\mathrm{~d}, J=8.6 \mathrm{~Hz}, 2 \mathrm{H}), 6.44-$ 6.29 (m, $1 \mathrm{H}), 6.24-6.05$ ( $\mathrm{m}, 1 \mathrm{H}), 2.75-2.57$ (m, $1 \mathrm{H}), 2.52-2.32$ (m, $3 \mathrm{H}), 2.29(\mathrm{~s}, 3 \mathrm{H}), 2.24-2.01(\mathrm{~m}, 4 \mathrm{H}), 1.88(\mathrm{dd}, J=3.4,8.3 \mathrm{~Hz}$, $1 \mathrm{H}), 1.74-1.59(\mathrm{~m}, 2 \mathrm{H})$; ${ }^{13} \mathrm{C}$ NMR $\left(50 \mathrm{MHz}, \mathrm{CDCl}_{3}\right) \delta_{\mathrm{C}}: 212.5$, 169.6, 149.6, 135.4, 130.7, 128.7, 126.9, 121.6, 77.7, 77.0, 76.4, 50.7, 42.2, 33.6, 33.0, 27.9, 25.1, 21.2; ESI-MS: $m / z 295.1$ [M + $\mathrm{Na}]^{+}$; HRMS (ESI): calcd. for $\mathrm{C}_{17} \mathrm{H}_{20} \mathrm{O}_{3} \mathrm{Na}[\mathrm{M}+\mathrm{Na}]^{+}$295.1305, found 295.1298 .

\section{Synthesis of compound 8}

A stirred solution of 1 'S-1'-acetoxychavicol acetate (2; $40 \mathrm{mg}$ ) was dissolved in dry $\mathrm{CH}_{2} \mathrm{Cl}_{2}(2 \mathrm{~mL})$ and degassed for $15 \mathrm{~min}$. Then Grubb's ${ }^{\text {st }}$ generation catalyst $(15 \mathrm{~mol} \%$ ) was added to the reaction mixture and stirring was continued for a further $16 \mathrm{~h}$ at room temperature under an argon atmosphere. After the completion of reaction (TLC), the solvent was removed under reduced pressure. The crude reaction mixture was flash chromatographed using RediSep ${ }^{\circledR}$ column $\left(\mathrm{SiO}_{2}, 12 \mathrm{~g}\right)$ and eluted with petroleum ether: ethyl acetate $(0 \rightarrow 20 \%)$ to furnish pure homodimer 8 as a colorless solid (68 mg, 91\%); $R_{\mathrm{f}} 0.30$ (EtOAc-petroleum ether, $3: 7)$; m.p. $83-85^{\circ} \mathrm{C} ;[\alpha]_{\mathrm{D}}^{25}-36.6\left(\mathrm{c} 1, \mathrm{CHCl}_{3}\right) ;{ }^{1} \mathrm{H} \mathrm{NMR}(400 \mathrm{MHz}$, $\left.\mathrm{CDCl}_{3}\right) \delta_{\mathrm{H}}: 7.34(\mathrm{~d}, J=8.7 \mathrm{~Hz}, 4 \mathrm{H}), 7.07(\mathrm{~d}, J=8.2 \mathrm{~Hz}, 4 \mathrm{H}), 6.27-$ 6.32 (m, $2 \mathrm{H}$ ), 5.90 (dd, J=2.7, $1.4 \mathrm{~Hz}, 2 \mathrm{H}$ ), 2.29 (s, $6 \mathrm{H}$ ), 2.09 (s, $6 \mathrm{H}) ;{ }^{13} \mathrm{C}$ NMR $\left(100 \mathrm{MHz}, \mathrm{CDCl}_{3}\right) \delta_{\mathrm{C}}: 169.9,169.5,150.6,136.3$, 130.6, 130.6, 128.6, 121.9, 74.4, 21.3, 21.2; ESI-MS: $m / z$ 463.1 [M $+\mathrm{Na}]^{+}$; HRMS (ESI): calcd. for $\mathrm{C}_{24} \mathrm{H}_{24} \mathrm{O}_{8} \mathrm{Na}[\mathrm{M}+\mathrm{Na}]^{+} 463.1363$, found 463.1351 .

\section{Antitubercular assay using the XTT reduction menadione assay protocol}

Crude extracts and pure compounds 1-8 were evaluated for their in vitro effects against the active and dormant phase of M. tuberculosis H37Ra (MTB) using the XRMA protocol [51]. M. tuberculosis H37Ra (ATCC 25177) was obtained from MTCC. MTB (ATCC No.25177) were grown to the logarithmic phase (O.D. 1.0) in a Mycobacterium phlei medium. The stock culture was maintained at $-70{ }^{\circ} \mathrm{C}$ and subcultured once in $M$. phlei medium before inoculation into the experimental culture. All experiments were performed in triplicate, and $\mathrm{IC}_{50}$ and MIC values were calculated from their dose-response curves.

\%Inhibition $=100-\left(A_{1}-\right.$ blank $) /\left(A_{2}-\right.$ blank $) \times 100$

where $A_{1}$ is the culture absorbance at $470 \mathrm{~nm}$ in the presence of the compound after the addition of menadione, $A_{2}$ is the culture absorbance at $470 \mathrm{~nm}$ (DMSO solvent control) after the addition of menadione, and blank is the culture absorbance at $470 \mathrm{~nm}$ of the respective data points before the addition of XTT/menadione [51].

\section{XTT reduction menadione assay protocol}

Activity against MTB was determined through the XRMA, reading absorbance at $470 \mathrm{~nm}$, as per the protocol [51]. A compound solution $(2.5 \mu \mathrm{L})$ was added in a total volume of $250 \mu \mathrm{L}$ of $M$. pheli medium consisting of the MTB, sealed with plate sealers and allowed to incubate for 8 (active phase) and 12 (dormant phase) days at $37^{\circ} \mathrm{C}$. The XRMA was then carried out to estimate the viable cells present in different wells of the assay plate. To all wells, $200 \mu \mathrm{M}$ of XTT were added and incubated at $37^{\circ} \mathrm{C}$ for another $20 \mathrm{~min}$. It was followed by the addition of $60 \mu \mathrm{M}$ of menadione and incubated at $37^{\circ} \mathrm{C}$ for $40 \mathrm{~min}$. The optical density was measured using a microplate reader (SpectraMax Plus 384 plate reader, Molecular Devices, Inc.) at $470 \mathrm{~nm}$ filter against a blank prepared from a well free of cells. Absorbance obtained from the cells treated with $1 \%$ DMSO alone was considered $100 \%$ cell growth. The \%inhibition in the presence of test material is calculated by using formula,

\%Inhibition $=($ average of control - average of compound $) /$ (average of control - average of blank) $\times 100$

where control is culture medium with cells and DMSO and blank are culture medium without cells. For all samples, each compound concentration was tested in triplicate in a single experiment and the quantitative value is expressed as the mean \pm standard deviation (S.D.). 


\section{Supporting information}

The general experimental procedures, extractions of the plant material, isolation of compounds, and antitubercular assay protocol as well as copies of their ${ }^{1} \mathrm{H},{ }^{13} \mathrm{C}$, DEPT, LCMS, and HRMS spectra are available as Supporting Information.

\section{Acknowledgments}

$\nabla$

This work was supported by the Council of Scientific and Industrial Research (CSIR)-New Delhi sponsored network projects, NaPAHA (CSC0130) and NORMS (CSC0406). The authors are grateful to Prof. Kornkanok Ingkainan, Department of Pharmaceutical Chemistry and Pharmacognosy, Faculty of Pharmaceutical Sciences, Naresuan University, Thailand for the collection and identification of A. galanga rhizomes.

\section{Conflict of Interest}

$\nabla$

The authors declare no conflict of interest.

\section{References}

1 World Health Organization. Global tuberculosis report: WHO report 2014. Geneva, Switzerland: WHO Press; 2014

2 Sankar MM, Singh J, Diana SCA, Singh S. Molecular characterization of Mycobacterium tuberculosis isolates from North Indian patients with extrapulmonary tuberculosis. Tuberculosis 2013; 93: 75-83

3 Young DB, Perkins MD, Duncan K, Barry CE. Confronting the scientific obstacles to global control of tuberculosis. J Clin Invest 2008; 118: 1255-1265

4 Lienhardt C, Vernon A, Raviglione MC. New drugs and new regimens for the treatment of tuberculosis: review of the drug development pipeline and implications for national programmes. Curr Opin Pulm Med 2010; 16: 186-193

5 Shaikh MH, Subhedar DD, Nawale L, Sarkar D, Khan FA, Sangshetti JN, Shingate BB. 1,2,3-Triazole derivatives as antitubercular agents: synthesis, biological evaluation and molecular docking study. Medchemcomm 2015; 6: 1104-1116

6 Singh MM. XDR-TB-danger ahead. Indian J Tuberc 2007; 54: 1-2

7 Rao K, Chodisetti B, Gandi S, Mangamoori LN, Giri A. Direct and indirect organogenesis of Alpinia galanga and the phytochemical analysis. Appl Biochem Biotechnol 2011; 165: 1366-1378

8 Gupta P, Bhatter P, D'souza D, Tolani M, Daswani P, Tetali P, Birdi T. Evaluating the anti Mycobacterium tuberculosis activity of Alpinia galanga (L.) Willd. axenically under reducing oxygen conditions and in intracellular assays. BMC Complement Altern Med 2014; 14: 84

9 Warrier PK, Nambiar VPK. Indian medicinal plants: a compendium of 500 species, Vol. 1. New Delhi: Orient Longman Pvt Ltd.; 1994: 104

10 Samarghandian S, Hadjzadeh M, Afshari JT, Hosseini M. Antiproliferative activity and induction of apoptotic by ethanolic extract of Alpinia galanga rhizhome in human breast carcinoma cell line. BMC Complement Altern Med 2014; 14: 192

11 Köse LP, Gülçin İ, Gören AC, NamiesnikJ, Martinez-Ayala AL, Gorinstein S. LC-MS/MS analysis, antioxidant and anticholinergic properties of galanga (Alpinia officinarum Hance) rhizomes. Ind Crops Prod 2015; 74: $712-721$

12 Khattak S, Shah HU, Ahmad W, Ahmad M. Biological effects of indigenous medicinal plants Curcuma longa and Alpinia galanga. Fitoterapia 2005; 76: 254-257

13 Bendjeddou $D$, Lalaoui $K$, Satta $D$. Immunostimulating activity of the hot water-soluble polysaccharide extracts of Anacyclus pyrethrum, Alpinia galanga and Citrullus colocynthis. J Ethnopharmacol 2003; 88: $155-160$

14 Akhtar MS, Khan MA, Malik MT. Hypoglycaemic activity of Alpinia galanga rhizome and its extracts in rabbits. Fitoterapia 2002; 73: 623-628

15 Chan EW, Ng VP, Tan VV, Low YY. Antioxidant and antibacterial properties of Alpinia galanga, Curcuma longa, and Etlingera elatior (Zingiberaceae). Pharmacog J 2011; 3: 54-61

16 Trakranrungsie N, Chatchawanchonteera A, Khunkitti W. Ethnoveterinary study for antidermatophytic activity of Piper betle, Alpinia galanga and Allium ascalonicum extracts in vitro. Res Vet Sci 2008; 84: 80-84
17 Oonmetta-Aree J, Suzuki T, Gasaluck P, Eumkeb G. Antimicrobial properties and action of galangal (Alpinia galanga Linn.) on Staphylococcus aureus. LWT Food Sci Technol 2006; 39: 1214-1220

18 Ling $\mathrm{ZH}$, Lv-Yi CH, Liang JY. Two new phenylpropanoids isolated from the rhizomes of Alpinia galanga. Chinese I Nat Med 2012; 10: 370-373

19 Xiao-Lu ZH, Ming-Hua YA, Jian-Guang LU, Huang XF, Ling-Yi KO. A new phenylpropanoid from Alpinia galanga. Chinese J Nat Med 2009; 7: 1920

20 Kubota K, Nakamura (Murayama) K, Kobayashi A, Amaike M. Acetoxy-1, 8 -cineoles as aroma constituents of Alpinia galanga Willd. J Agric Food Chem 1998; 46: 5244-5247

21 Barik BR, Kundu AB, Dey AK. Two phenolic constituents from Alpinia galanga rhizomes. Phytochemistry 1987; 26: 2126-2127

22 De Pooter HL, Omar MN, Coolsaet BA, Schamp NM. The essential oil of greater galanga (Alpinia galanga) from Malaysia. Phytochemistry 1985; 24: 93-96

23 Yang WQ Gao Y, Li M, Miao DR, Wang F. New chalcones bearing a longchain alkylphenol from the rhizomes of Alpinia galanga. J Asian Nat Prod Res 2015; 17: 783-787

24 Roy SK, Pahwa S, Nandanwar H, Jachak SM. Phenylpropanoids of Alpinia galanga as efflux pump inhibitors in Mycobacterium smegmatis $\mathrm{mc}^{2}$ 155. Fitoterapia 2012; 83: 1248-1255

25 Singh JH, Alagarsamy V, Diwan PV, Kumar SS, Nisha JC, Reddy YN. Neuroprotective effect of Alpinia galanga (L.) fractions on $A \beta(25-35)$ induced amnesia in mice. J Ethnopharmacol 2011; 138: 85-91

26 Latha C, Shriram VD, Jahagirdar SS, Dhakephalkar PK, Rojatkar SR. Antiplasmid activity of 1'-acetoxychavicol acetate from Alpinia galanga against multi-drug resistant bacteria. J Ethnopharmacol 2009; 123: 522-525

27 Phitak T, Choocheep K, Pothacharoen P, Pompimon W, Premanode B, Kongtawelert $P$. The effects of p-hydroxycinnamaldehyde from Alpinia galanga extracts on human chondrocytes. Phytochemistry 2009; 70: 237-243

28 Yasuhara T, Manse Y, Morimoto T, Qilong W, Matsuda H, Yoshikawa M, Muraoka $O$. Acetoxybenzhydrols as highly active and stable analogues of 1'S-1'-acetoxychavicol, a potent antiallergic principal from Alpinia galanga. Bioorg Med Chem Lett 2009; 19: 2944-2946

29 Matsuda H, Pongpiriyadacha Y, Morikawa T, Ochi M, Yoshikawa M. Gastroprotective effects of phenylpropanoids from the rhizomes of Alpinia galanga in rats: structural requirements and mode of action. Eur J Pharmacol 2003; 471: 59-67

30 Tamura S, Shiomi A, Kimura T, Murakami N. Halogenated analogs of 1'acetoxychavicol acetate, Rev-export inhibitor from Alpinia galanga, designed from mechanism of action. Bioorg Med Chem Lett 2010; 20 : 2082-2085

31 Tamura S, Shiomi A, Kaneko M, Ye Y, Yoshida M, Yoshikawa M, Kimura T, Kobayashi M, Murakami N. New Rev-export inhibitor from Alpinia galanga and structure-activity relationship. Bioorg Med Chem Lett 2009; 19: $2555-2557$

32 Hasima N, Aun LI, Azmi MN, Aziz AN, Thirthagiri E, Ibrahim H, Awang K. 1'S-1'-Acetoxyeugenol acetate: a new chemotherapeutic natural compound against MCF-7 human breast cancer cells. Phytomedicine 2010; 17: $935-939$

33 Matsuda H, Ando S, Morikawa T, Kataoka S, Yoshikawa M. Structure-activity relationships of 1 'S-1'-acetoxychavicol acetate for inhibitory effect on NO production in lipopolysaccharide-activated mouse peritoneal macrophages. Bioorg Med Chem Lett 2005; 15: 1949-1953

34 Zeng $Q H$, Lu CL, Zhang XW, Jiang JG. Isolation and identification of ingredients inducing cancer cell death from the seeds of Alpinia galanga, a Chinese spice. Food Funct 2015; 6: 431-443

35 Phanthong P, Lomarat P, Chomnawangb MT, Bunyapraphatsaraa N. Antibacterial activity of essential oils and their active components from Thai spices against foodborne pathogens. Sci Asia 2013; 39: 472-476

36 Kubota K, Ueda Y, Yasuda M, Masuda A. Occurrence and antioxidative activity of 1 -acetoxychavicol acetate and its related compounds in the rhizomes of Alpinia galanga during cooking. In: Spanier AM, Shahidi F, Parliment TH, Mussinan C, Ho CT, Tratras Contis E, editors. Food flavors and chemistry: advances of the new millennium. Cambridge, UK: The Royal Society of Chemistry 2001; 274: 601-607

37 Moffatt J, Hashimoto M, Kojima A, Kennedy DO, Murakami A, Koshimizu $K$, Ohigashi H, Matsui-Yuasa I. Apoptosis induced by 1 '-acetoxychavicol acetate in Ehrlich ascites tumor cells is associated with modulation of polyamine metabolism and caspase-3 activation. Carcinogenesis 2000; 21: $2151-2157$ 
38 Itokawa H, Morita H, Sumitomo T, Totsuka N, Takeya K. Antitumour principles from Alpinia galanga. Planta Med 1987; 53: 32-33

39 Kondo A, Ohigashi H, Murakami A, Suratwadee J, Koshimizu K. 1'-acetoxychavicol acetate as a potent inhibitor of tumor promoter-induced Epstein-Barr virus activation from Languas gaianga, a traditional Thai condiment. Biosci Biotechnol Biochem 1993; 57: 1344-1345

40 Zheng Q Hirose Y, Yoshimi N, Murakami A, Koshimizu K, Ohigashi H, Sakata K, Matsumoto $Y$, Sayama Y, Mori $H$. Further investigation of the modifying effect of various chemopreventive agents on apoptosis and cell proliferation in human colon cancer cells. J Cancer Res Clin Oncol 2002; 128: 539-546

41 Murakami A, Toyota K, Ohura S, Koshimizu K, Ohigashi H. Structure-activity relationships of (1'S)-1'-acetoxychavicol acetate, a major constituent of a southeast Asian condiment plant Languas galanga, on the inhibition of tumor-promoter-induced Epstein-Barr virus activation. J Agric Food Chem 2000; 48: 1518-1523

42 Nakamura Y, Murakami A, Ohto Y, Torikai K, Tanaka T, Ohigashi H. Suppression of tumor promoter-induced oxidative stress and inflammatory responses in mouse skin by a superoxide generation inhibitor 1'acetoxychavicol acetate. Cancer Res 1998; 58: 4832-4839

43 Noro T, Sekiya T, Katoh M, Oda Y, Miyase T, Kuroyanagi M, Ueno A, Fukushima S. Inhibitors of xanthine oxidase from Alpinia galanga. Chem Pharm Bull 1988; 36: 244-248

44 Janssen AM, Scheffer JJ. Acetoxychavicol acetate, an antifungal component of Alpinia galangal. Planta Med 1985; 51: 507-511

45 Bhattacharya AK, Chand HR, John J, Deshpande MV. Clerodane type diterpene as a novel antifungal agent from Polyalthia longifolia var. pendula. Eur J Med Chem 2015; 94: 1-7

46 Bhattacharya AK, Rana KC. Antimycobacterial agent, (E)-phytol and lauric amide from the plant Lagascea mollis. Ind J Chem 2013; $52 \mathrm{~B}$ : 901-903

47 Bhattacharya AK, Pathak AK, Sharma RP. Semi-synthesis of deoxyartemisinin. Mendeleev Commun 2007; 17: 27-28

48 Bhattacharya AK, Pal M, Jain DC, Joshi BS, Roy R, Rychlewska U, Sharma $R P$. Stereoselective reduction of arteannuin $B$ and its chemical transformations. Tetrahedron 2003; 59: 2871-2876

49 Bhattacharya AK, Jain DC, Sharma RP, Roy R, McPhail AT. Boron trifluoride-acetic anhydride catalysed rearrangement of dihydroarteannuin $B$. Tetrahedron 1997; 53: 14975-14990
50 Sarkar S, Sarkar D. Potential use of nitrate reductase as a biomarker for the identification of active and dormant inhibitors of Mycobacterium tuberculosis in a THP1 infection model. J Biomol Screening 2012; 17: 966-973

51 Singh U, Akhtar S, Mishra A, Sarkar D. A novel screening method based on menadione mediated rapid reduction of tetrazolium salt for testing of anti-mycobacterial agents. J Microbiol Methods 2011; 84: 202-207

52 Khan A, Sarkar S, Sarkar D. Bactericidal activity of 2-nitroimidazole against the active replicating stage of Mycobacterium bovis BCG and Mycobacterium tuberculosis with intracellular efficacy in THP-1 macrophages. Int J Antimicrob Agents 2008; 32: 40-45

53 Ibrahem I, Córdova A. Direct catalytic intermolecular $\alpha$-allylic alkylation of aldehydes by combination of transition-metal and organocatalysis. Angew Chem Int Ed 2006; 45: 1952-1956

54 Rosebrugh LE, Herbert MB, Marx VM, Keitz BK, Grubbs RH. Highly active ruthenium metathesis catalysts exhibiting unprecedented activity and Z-selectivity. J Am Chem Soc 2013; 35: 1276-1279

received April 27, 2016

revised June 17,2016

accepted July 4, 2016

Bibliography

DOI http://dx.doi.org/10.1055/s-0042-112226

Planta Med Int Open 2016; 3: e55-e59

(c) Georg Thieme Verlag KG Stuttgart · New York .

ISSN 2509-6656

Correspondence

\section{Dr. Asish K. Bhattacharya}

Division of Organic Chemistry

CSIR-National Chemical Laboratory (CSIR-NCL)

Dr. Homi Bhabha Road

Pune 411008

India

Phone: + 912025902309

Fax: + 912025902269

ak.bhattacharya@ncl.res.in 